\title{
Effectiveness of Short-Term Physical Agents Treatment on Macroscopic Morphology in Patients with Plaque Psoriasis
}

\author{
Efectividad del Tratamiento A Corto Plazo de los Agentes Físicos \\ en la Morfología Macroscópica de las Placas de Psoriasis
}

\author{
Leandra Norambuena-Mardones ${ }^{1}$; Dominique Evelyn Pinto-Daza ${ }^{1}$; Karla Daniela Troncoso-Fernández; \\ Alejandro Pacheco' ${ }^{1}$; Kaio Fernando Vitzel $^{2}$ \& Gabriel Nasri Marzuca-Nassr ${ }^{3}$
}

\begin{abstract}
NORAMBUENA-MARDONES, L.; PINTO-DAZA, D. E.; TRONCOSO-FERNÁNDEZ, K. D.; PACHECO, A.; VITZEL, K. F. \& MARZUCA-NASSR, G. N. Effectiveness of short-term physical agents treatment on macroscopic morphology in patients with plaque psoriasis. Int. J. Morphol., 37(4):1541-1550, 2019.

SUMMARY: Psoriasis is a chronic inflammatory disease that presents skin rashes which can arise through plaques. The aim of this work was to compare the effectiveness of short-term physical agents treatment on macroscopic morphology (area and erythema) in patients with plaque psoriasis. This prospective randomized experimental study included fourteen subjects, medically diagnosed with psoriasis, with more than one plaque in the skin and voluntarily without topical treatment. All subjects completed the study that consisted of 12 treatment sessions divided in control (C), artificial balneotherapy (AB), phototherapy (PT) or balneophototherapy (BPT) groups. After session 12, there was a significant reduction of the plaque area by all treatments when compared to $\mathrm{C}$ group and BPT was the most effective one. However, only AB and PT presented a reduction of erythema. Regarding severity, 9 patients changed to a lower category on the PASI test, and 5 of them maintained a mild psoriasis, but lowered their score. Finally, 13 of 14 subjects improved their quality of life. The physical agents used reduced the severity of psoriasis and improved quality of life of patients after 12 sessions of treatment during a onemonth period. The BPT was the more effective in controlling psoriasis by diminishing its area and PT by attenuating the erythema.
\end{abstract}

KEY WORDS: Psoriasis; Balneotherapy; Phototherapy; Balneophototherapy.

\section{INTRODUCTION}

Psoriasis is a chronic inflammatory disease (e.g. increase serum levels of tumor necrosis factor-alfa [TNF-

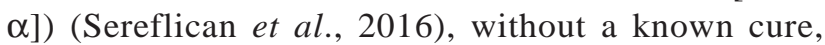
characterized by "rashes" in the skin, commonly presented as plaques, which are manifested by the appearance of scales and redness in the affected skin (Londoño et al., 2009). These plaques may be troublesome if they are present in joints and/or visible areas, reason why the subject is constantly searching for treatments to control it. The therapeutic tools include topical treatments, oral medications and the application of physical agents such as: artificial balneotherapy (AB), phototherapy (PT) and artificial balneophototherapy (BPT) (Londoño et al.; Kogan et al., 2019).

$\mathrm{AB}$ is the immersion of injured skin in solutions with high concentration of sea salt, allowing the minerals to penetrate through the skin. It can induce different physiological responses, such as microcirculatory vasodilation, decrease of muscle tone, pain reduction and immune response inhibition (Katz et al., 2012).

PT consists of short and periodic sessions of ultraviolet B light (UV-B) exposure. Immunomodulatory effects are attributed to the UV-B, in part due to its capability to modulate Langerhans cells migration and suppress their ability to promote immune responses (Wong et al., 2013). The UV-B reduces the number of Langerhans cells in the epidermis, mainly by increasing the migration from the skin to subcutaneous lymph nodes, but also by promoting apoptosis (Wong et al.). In addition, UV-B penetrates up to the epidermis and counteracts the skin damage caused by psoriasis. It causes damage in cell membranes and DNA, leading to apoptosis of keratinocytes

\footnotetext{
${ }^{1}$ School of Kinesiology, Faculty of Health Sciences, Universidad Católica del Maule, Talca, Chile.

${ }^{2}$ School of Health Sciences, College of Health, Massey University, Auckland, New Zealand.

${ }^{3}$ Department of Internal Medicine, Faculty of Medicine, Universidad de La Frontera, Temuco, Chile.

This study was financed by Universidad de La Frontera, Proyecto DI17-6002 and Proyecto FONDECYT Nº11180949.
} 
and lymphocytes depletion at the psoriatic epidermis and, in a lower extent, at the dermis (Wong et al.). It increases de expression of IL-4, IL-5, IL-10, and COX-2 (Gambichler et $a l ., 2015)$ and decreases the expression of IL-6, IL-12, IL17A, and in keratinocytes (Batycka-Baran et al., 2016).

BPT is a combination of $\mathrm{AB}$ and PT, simulating the climatotherapy of specific locations, such as the Dead Sea. When immersing psoriatic skin in a warm bath with sea salt, the tissue rapidly absorbs certain substances of the water, increasing its photosensitivity to UV-B light. BPT blocks cell division, stops cutaneous cell hyperproliferation and reduces inflammation (Léauté-Labrèze et al., 2001; Katz et al.; Gambichler et al.).

$\mathrm{AB}$ and PT are effective treatments for psoriasis. Also, it is know that the combination of both is more effective than the application of one method alone in a long-term treatment. However, only a few studies compare the benefits of AB, PT and BPT, especially the early effects of the treatment, after only 12 session of treatment during a onemonth period. In this study, we compare the effectiveness of $\mathrm{AB}, \mathrm{PT}$ and BPT in the treatment of plaque psoriasis, evaluating the plaque area, alteration of skin pigmentation, the Psoriasis Area and Severity Index (PASI) score and assessing quality-of-life by Short Form 36 Health Survey (SF-36) and Psoriasis Disability Index (PDI) scores during the month of treatment.

\section{MATERIAL AND METHOD}

Design and study population. It was carried out a prospective and randomized experimental study, in the Kinesiology School with the approval of the Bioethics Committee of University of Catholic University of Maule, Chile. The Consolidated Standards of Reporting Trials (CONSORT) Statement was used as a guideline for the study (Fig. 1).

Selection and division of the study population. The sample consisted of 7 men and 7 women (37.85 \pm 9.85 years-old) and their psoriatic plaques were correlatively ordered. A total of 58 plaques were randomly assigned for treatment in one of the 4 groups: control group (C) $(n=14)$, AB group $(n=15)$, PT group $(n=14)$, BPT group $(n=15)$.

First, an interview was carried out to all subjects in order to inform the type of study that they would be part of, without telling them the kind of therapies to be used to treat their plaques, and to select those who met the following inclusion criteria: be more than 18 years-old, have more than one plaque on the skin, medically diagnosed as plaque psoriasis over a year ago and without concurrent topical treatment for Psoriasis (by own choice); and exclusion criteria: pregnancy, skin carcinoma, severe diabetes mellitus, uncontrolled chronic pathologies and/or severe cardiac/renal insufficiency and/or acute infections.

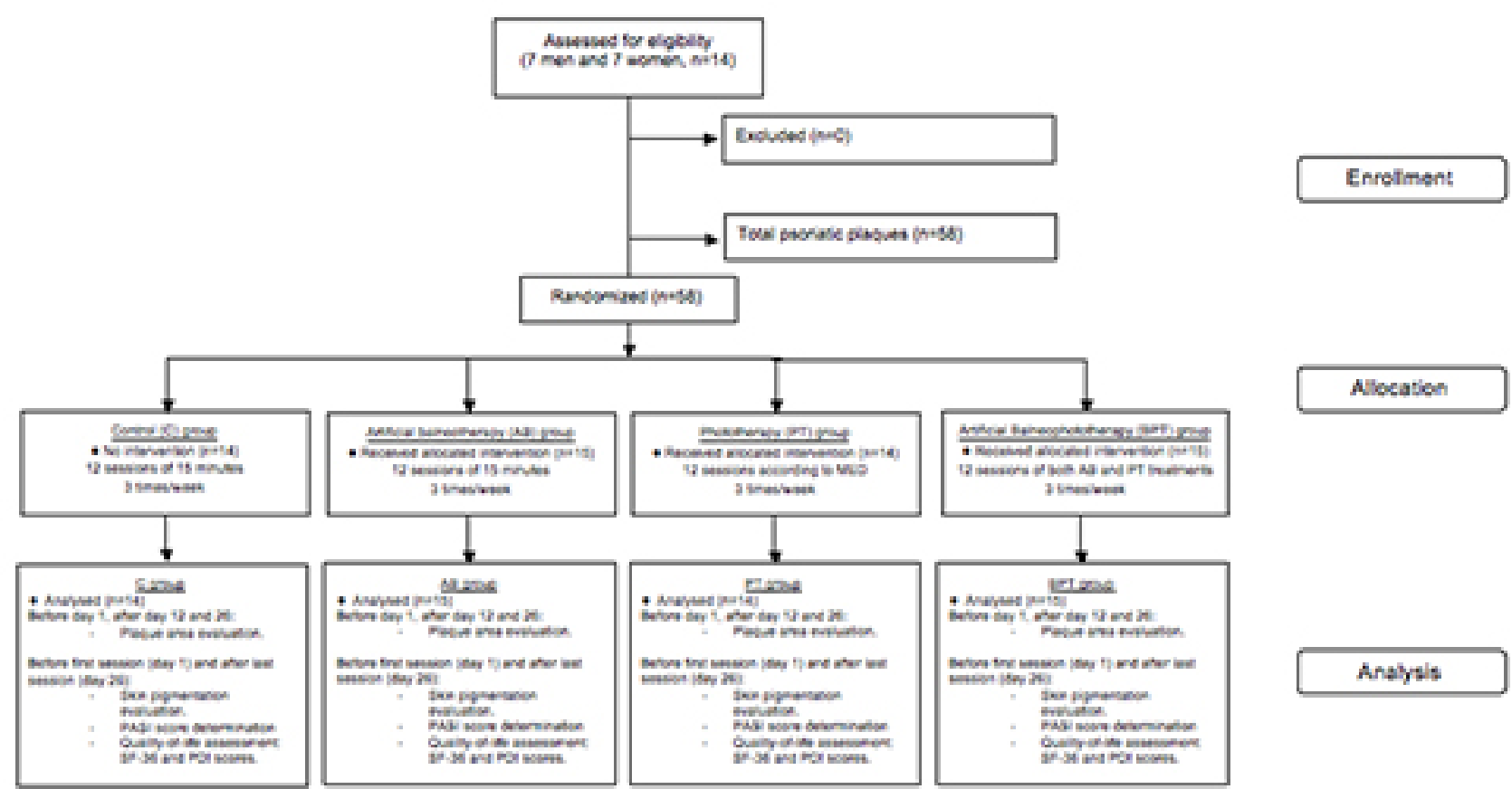

Fig. 1. Consolidated Standards of Reporting Trials (CONSORT) flow diagram of the randomized trial. C: control; AB: artificial balneotherapy, PT: phototherapy; BPT: balneophototherapy; MED: Minimal Erythema Dose; PASI: Psoriasis Area and Severity Index; SF-36: Short Form 36 Health Survey; PDI: Psoriasis Disability Index. 
On the selected subjects, it was also performed the evaluation of Minimal Erythema Dose (MED) in order to determine an acceptable dose of UV-B light for the type of skin of each patient. Thus, the evaluations were performed according to psoriasis type, area, color and plaques severity (Heckman $e t$ al., 2013). The formula used for the calculation was:

$$
\mathrm{MED}=2 \times \mathrm{t}(\mathrm{s}) \times 0.75
$$

t: minimum time for erythema occurrence

Each psoriatic plaque was submitted to three therapeutic sessions per week, during 4 weeks, for a total of 12 sessions.

For the application of $\mathrm{AB}$, the $\mathrm{AB}$ group plaques were immersed during 15 minutes in a 35 or $75 \mathrm{~L}$ hydrotherapy whirlpool (TB-T45 model and TB-T90 model respectively, Enraf Nonius Company SA, Spain) filled with a solution of warm water $\left(32^{\circ} \mathrm{C}\right)$ and natural sea salt $(250 \mathrm{~g} / \mathrm{L})$, following the protocol described by Schempp et al. (1999) and Schiener et al. (2007), always ensuring that the plaques not receiving this treatment were kept isolated with flexible and insulating adhesive patches (Nexcare ${ }^{\circledR}$ Factory $3 \mathrm{M}$, Chile).

For the implementation of PT, the PT group plaques that would not receive radiation were covered with thick cloth towels, while the healthy skin surrounding the treated plaques were coated with liquid petroleum jelly. Both patients and attendant were protected with special lenses with filter against UV light (Oakley Jupiter, USA). UV-B radiation was applied with the UV Endolamp 474 device (Enraf Nonius Company SA, Spain), $60 \mathrm{~cm}$ away from the plaque and in a perpendicular position. In session 1, the MED was calculated for each subject and used as the time of UV-B exposure. On each further session, the exposure time was increased by $25 \%$, until the limit of 5 minutes (Heckman et al.).

The BPT group plaques received both $\mathrm{AB}$ and PT treatments following the similar protocol of Schempp et al. (1999) and Schiener et al. on the same conditions described above, consecutively.

The $\mathrm{C}$ group plaques did not receive any treatment.

Data Collection. The plaques were photographed at a distance of $20 \mathrm{~cm}$ with a 12 megapixel Lumix digital camera (Panasonic, USA). For area quantification, the photographs were taken before session 1 and a day after session 6 and 12 , and were analyzed with Image J software (version 1.46j; National Institute of Health, MD, USA). For color evaluation, the photographs taken before session 1 and after session 12 were analyzed with the Average color seeker software (Version 0.41; IDimager Systems Inc., Scotts Valley, CA, USA), which uses the Red-Green-Blue (RGB) coordinates system to report the information about the red color channel, associated to erythema occurrence, in arbitrary units. Therefore, greater red color measurements for skin pigmentation may indicate increased erythema.

The psoriatic plaque severity was assessed before session 1 and one day after session 12 through PASI, which considers erythema, induration and plaque scaling, being 72 points the maximum score (Schmitt \& Wozel, 2005).

Quality of life assessment was performed using the SF-36 TM v2 health questionnaire, validated for the Chilean population (Olivares, 2005), and the PDI (Finlay et al., 1990), both performed before session 1 and one day after session 12.

Statistical Analysis. Data was analyzed using GraphPad Prism software (version 5.01; Inc., El Camino Real, CA, USA) and presented as mean \pm standard deviation for area and erythema. Plaque severity and quality of life were presented as percentage of initial value. A reduction of $75 \%$ on plaque severity was considered effective (Puig, 2007). Shapiro-Wilk was used as normality test. The analysis of intragroup differences of plaque area between sessions 1, 6 and 12 was performed using repeated measures ANOVA followed by Bonferroni post-test. Intragroup differences of erythema between session 1 and 12 were analyzed by paired t-test. The intergroup differences of plaque area and erythema were compared using two-way ANOVA followed by Bonferroni post-test. Differences were considered significant for $\mathrm{P}<0.05$.

\section{RESULTS}

The existing differences between $\mathrm{C}, \mathrm{AB}, \mathrm{PT}$ and BPT groups on sessions 1, 6 and 12 are shown on Figure 2. During the 4 weeks of treatment, a qualitative evaluation showed that, on $\mathrm{C}$ group, the plaques maintained initial area and increased scaling; in the $\mathrm{AB}$ group there was attenuation of erythema, scaling and induration; in the PT group there was a decrease in the area, erythema and scaling; and in BPT group there was a decrease in the area, erythema, scaling and induration of the plaques. In relation to the above, BPT presented the most effective results in reducing the characteristics of plaque psoriasis.

For $\mathrm{C}$ group, the plaque area had an average increase of $1.26 \%$ when measured a day after session 6 and $8.22 \%$ 


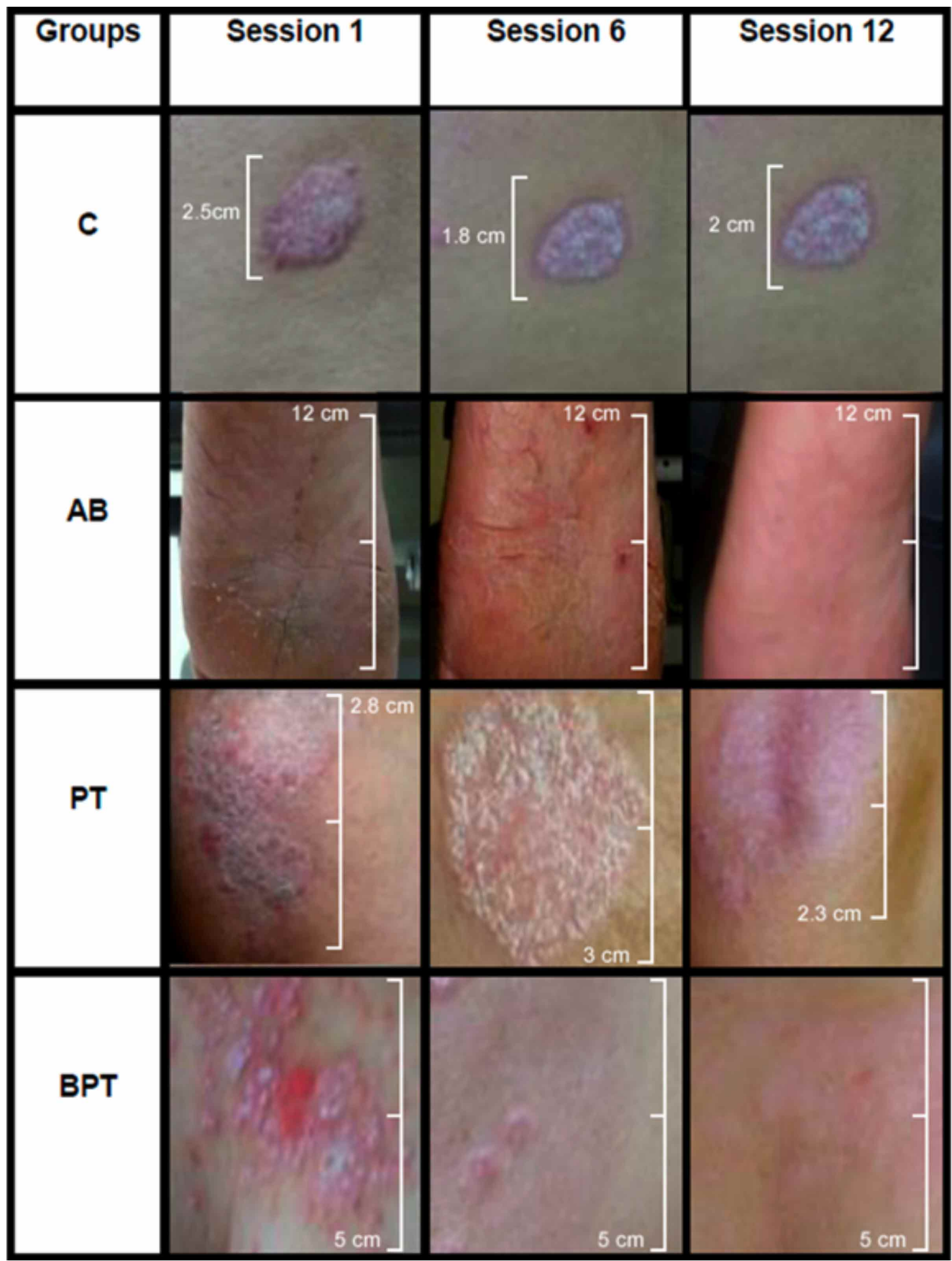

Fig. 2. Comparison of the evolution of macroscopic morphology of the plaques on treatment session 1, 6 and 12 in the different groups. All the pictures were taken at a distance of $20 \mathrm{~cm}$ from the plaques. C: control; AB: artificial balneotherapy, PT: phototherapy; BPT: balneophototherapy. C group: pictures from the abdominal area; $\mathrm{AB}$ group: pictures from the plantar region of the foot; PT group: pictures from the elbow area; BTP group: pictures from the sacrum area. 
a day after session 12 , although this difference was not significant $(\mathrm{P}=0.32$ ) (Fig. 3A); regarding erythema, there was a slight and not significant increase $(\mathrm{P}=0.28)$ of 4.23 $\%$ on red color evaluation of the plaques (Fig. 3B) after session 12.

For the $\mathrm{AB}$ group, the plaque area displayed an average decrease of $8.04 \%$ in session 6 and a significant decrease of $15.7 \%$ after session $12(\mathrm{P}<0.01)$ (Fig. 3C);
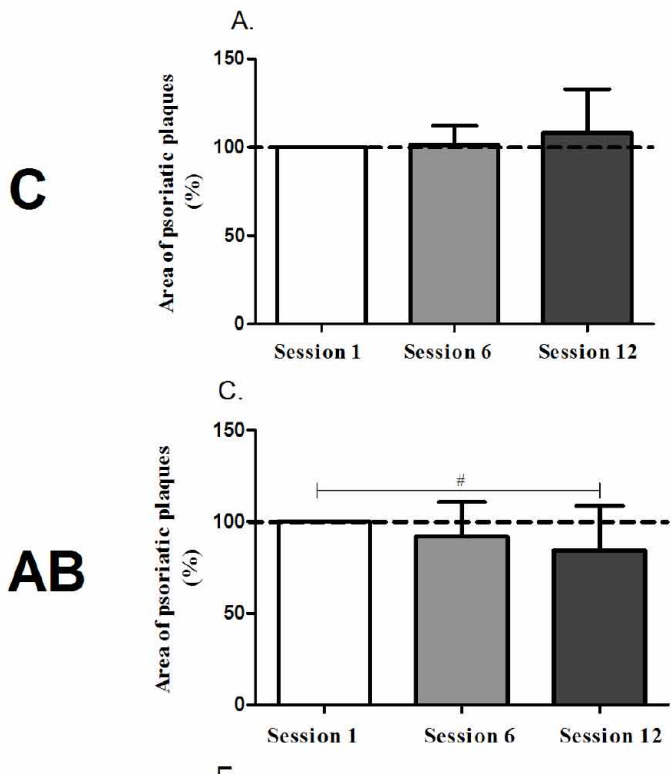

regarding erythema, there was a decrease of $5.7 \%$ on red color evaluation after session 12, which was not significant $(\mathrm{P}=0.3)$ (Fig. 3D).

For PT group, the plaque area showed an average decrease of $15.74 \%$ in session $6(\mathrm{P}<0.05)$ and $21.11 \%$ after session $12(\mathrm{P}<0.001)$ (Fig. 3E); regarding erythema, there was a significant decrease of $9.13 \%$ after session $12(\mathrm{P}<0.05)$ (Fig. 3F).
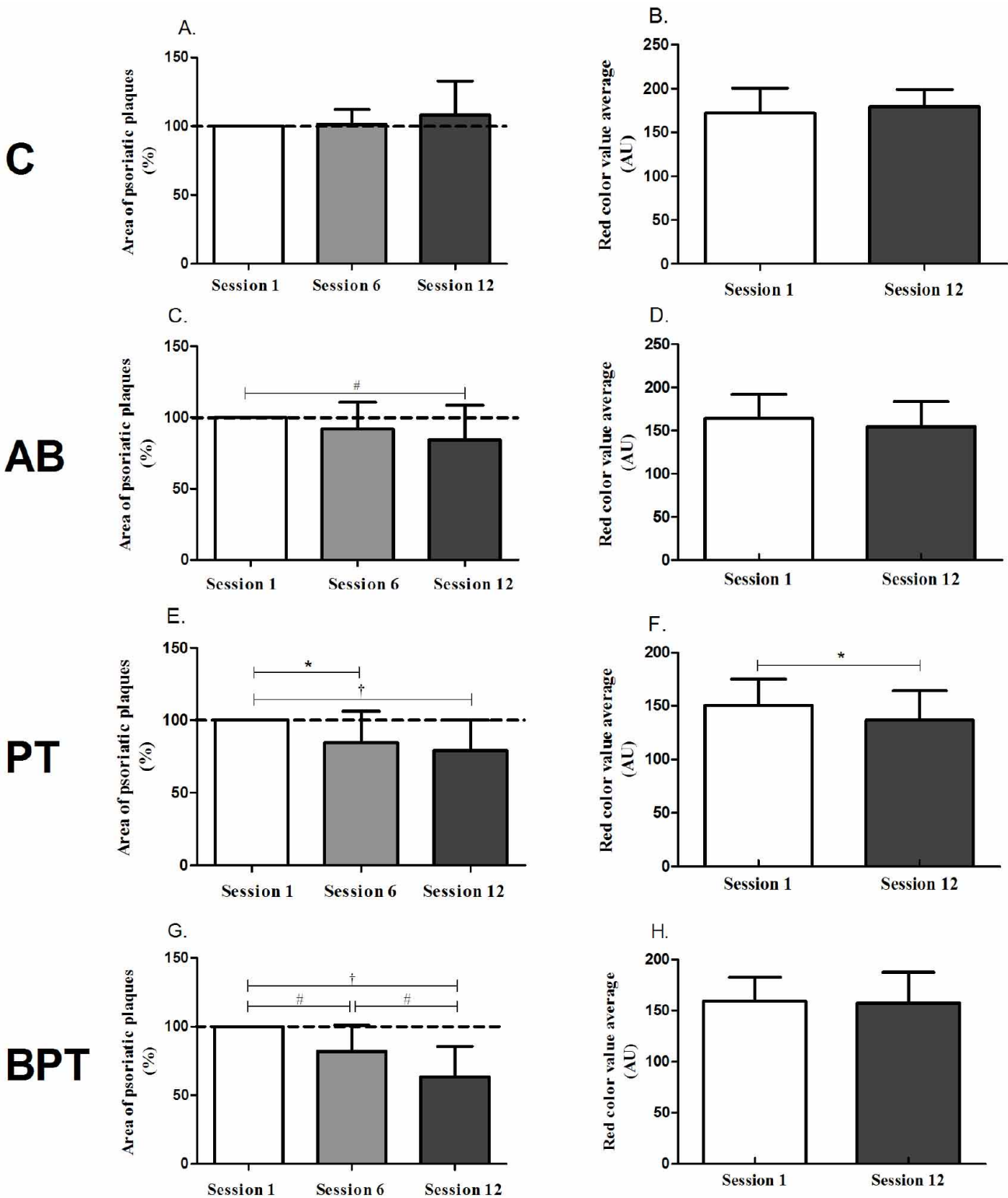

Fig. 3. Intragroup differences of the plaques in the percentage of total area (sessions 1,6 and 12) and red color value average (sessions 1 and 12). (A.) (B.) C group, (C.) (D.) AB group, (E.) (F.) PT group and (G.) (H.) BPT group. Values are presented as mean \pm SD, $n=14-15$ plaques. The results of percentage of total area were compared using repeated measures ANOVA followed by Bonferroni post-test and the results of red color value average were compared using paired t-test. C: control; AB: artificial balneotherapy, PT: phototherapy; BPT: balneophototherapy. * $\mathrm{P}<0.05$; \# $\mathrm{P}<0.01 ; \uparrow \mathrm{P}<0.001$. 
For BPT group, the plaque area had an average decrease of $17.91 \%$ after session $6(\mathrm{P}<0.01)$ and $36.31 \%$ after session $12(\mathrm{P}<0.001)$. Also, there was a significant decrease of plaque area when comparing sessions 6 vs. 12 $(\mathrm{P}<0.01)$ (Fig. 3G); regarding erythema, there was a reduction of $1.34 \%$ on plaques red color evaluation after 12 sessions of treatment, but it was not significant $(\mathrm{P}=0.83)$ (Fig. 3H).

When comparing the intergroup plaque area variation during the 4 weeks of treatment, the PT and BPT groups showed a significant reduction of plaque area when compared to $\mathrm{C}$ group $(\mathrm{P}<0.05$ and $\mathrm{P}<0.01$, respectively) in session 6 (Fig. 4A). After the last session, all the treatments presented a significant reduction of plaque area when compared to $\mathrm{C}$ group $(\mathrm{P}<0.001)$ (Fig. 4A).
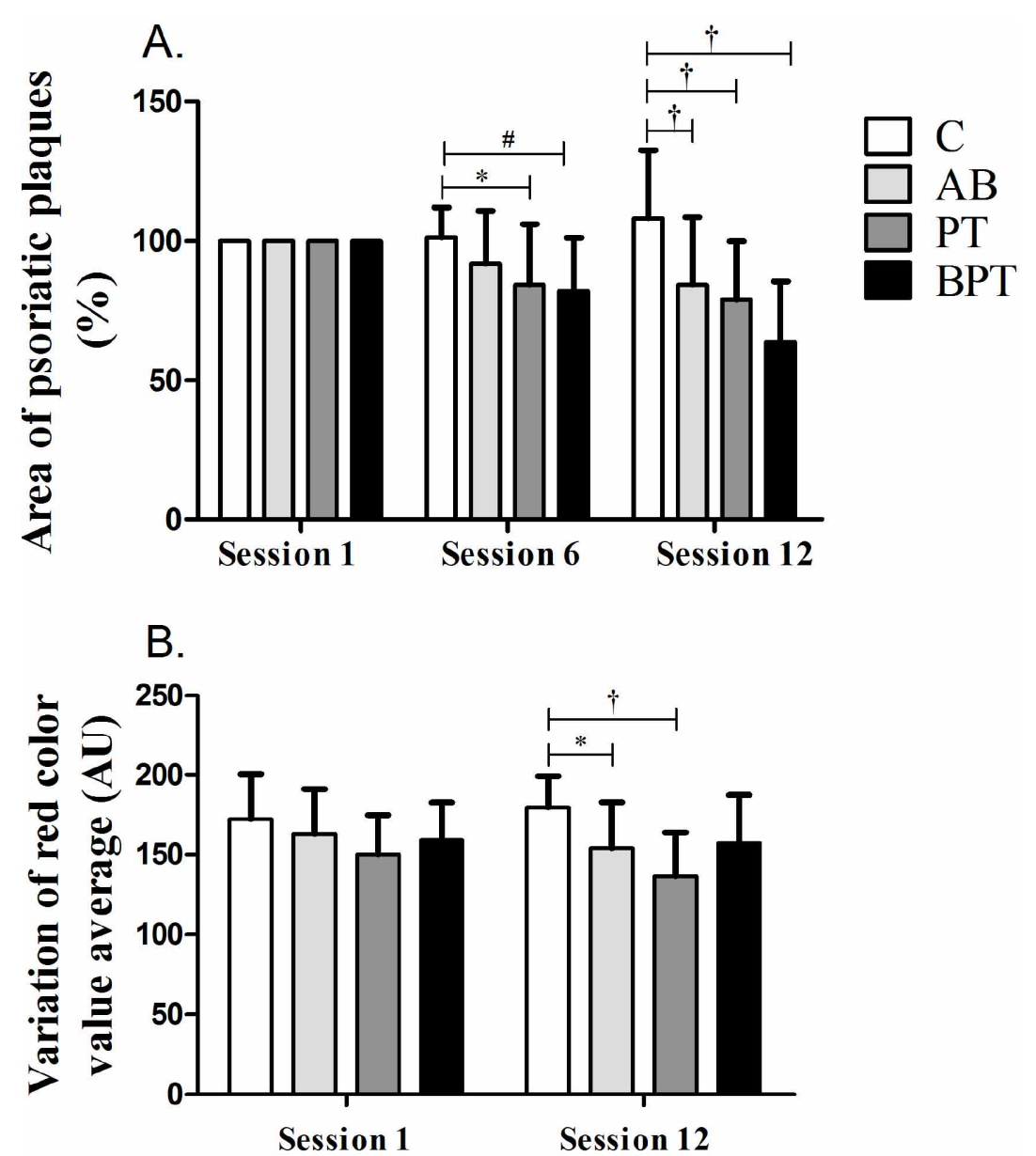

Fig. 4. Intergroup differences of the plaques in the (A.) percentage of total area (sessions 1,6 and 12) and in the (B.) variation of red color value average (sessions 1 and 12). Values are presented as mean $\pm \mathrm{SD}, \mathrm{n}=14-15$ plaques. The results were compared using two-way ANOVA followed by Bonferroni post-test. C: control; AB: artificial balneotherapy, PT: phototherapy; BPT: balneophototherapy; AU: arbitrary units. ${ }^{*} \mathrm{P}<0.05$; \# $\mathrm{P}<0.01 ; \dagger \mathrm{P}<0.001$.
When comparing intergroup erythema, only $\mathrm{AB}$ and $\mathrm{PT}$ presented a reduction of red color quantification after 12 sessions of treatment when compared to $\mathrm{C}$ group $(\mathrm{P}<0.05$ and $\mathrm{P}<0.01$, respectively) (Fig. 4B).

According to the initial PASI assessment, 5 patients presented mild, 4 moderate, and 5 severe psoriasis. Nine of the 14 patients were subjected to more than one treatment, 3 patients received only one treatment and 2 patients did not receive any treatment (control only). When comparing the initial and final PASI results, 4 patients presented a score reduction of more than $75 \%$ (PASI 75), 7 presented a reduction between $50 \%$ and $62.5 \%$ (PASI 50) and the remaining 3 had a decrease in their score of $9.8 \%, 12.5 \%$ and $43.1 \%$. Also, 9 patients had a decrease in the categorization of psoriasis, while the other 5 , that were already classified as mild, did not present alteration. However, all of them showed a score reduction by the end of treatment. The only 2 patients that did not receive any treatment were the ones that presented the lowest PASI score reductions $(9.8 \%$ and $12.5 \%$ ) (Table I).

When assessing quality of life with the SF-36 questionnaire, women showed greater affliction by psoriasis based on the average initial scores. The final average scores presented an increase for both sexes (women: 31.8 $\%$; men: $13.4 \%$ ). It is important to mention that, in this scale, a higher score is associated with a lower impact on quality of life. From the 14 subjects, 13 had positive changes; so just one patient had decreased his/ her quality of life during the intervention obtaining a value of -0.6 $\%$ compared to the initial score. The dimensions that had a greater change were bodily pain, physical function and physical role, all belonging to the physical health component of the SF36 (Table II).

According to the PDI questionnaire, there was a tendency of women being more affected by psoriasis then men (Student's t test; $\mathrm{P}=0.09$ ). The average final scores were 1.1 for both sexes. Then, the women presented a reduction of 88.2 
$\%$ and $80.7 \%$ for men. In PDI, unlike the SF-36, a higher score means greater impact on quality of life. All patients presented a positive change when relating the initial score with the final one, and 7 out of 14 patients displayed a full recovery, based on the questionnaire - final score of 0 (Table II).

Table I Summary table with initial and final values of the PASI, percentage of the change, sex and treatment received by each patient.

\begin{tabular}{cclccccc}
\hline Subject & Sex & Treatment & IE & IC & FE & FC & \% decrease \\
\hline 1 & F & C, BPT & 9.2 & Moderate & 4.6 & Mild & 50.0 \\
2 & F & C & 4.1 & Mild & 3.7 & Mild & 9.8 \\
3 & M & AB & 5.2 & Mild & 2.4 & Mild & 53.8 \\
4 & F & AB, BPT & 20.0 & Severe & 1.2 & Mild & 94.0 \\
5 & F & C, AB, PT, BPT & 16.0 & Severe & 4.0 & Mild & 75.0 \\
6 & F & C, PT, BPT & 8.0 & Moderate & 0.6 & Mild & 92.5 \\
7 & M & AB, BPT & 4.6 & Mild & 1.8 & Mild & 60.9 \\
8 & M & BPT & 8.4 & Moderate & 3.8 & Mild & 54.8 \\
9 & F & BPT & 9.6 & Moderate & 3.6 & Mild & 62.5 \\
10 & M & C, AB, PT & 34.5 & Severe & 7.8 & Moderate & 77.4 \\
11 & M & C, PT, BPT & 4.6 & Mild & 2.2 & Mild & 52.2 \\
12 & M & C & 3.2 & Mild & 2.8 & Mild & 12.5 \\
13 & F & C, PT, BPT & 18.0 & Severe & 7.2 & Moderate & 60.0 \\
14 & M & C, AB, PT, BPT & 20.9 & Severe & 11.9 & Moderate & 43.1 \\
\hline
\end{tabular}

PASI: Psoriasis Area and Severity Index; F: female; M: male; C: control; AB: artificial balneotherapy; PT: phototherapy; BPT: balneophototherapy; IE: initial evaluation; IC: initial classification; FE: final evaluation; FC: final classification.

Table II Comparative table of quality of life questionnaires between men and women.

\begin{tabular}{|c|c|c|c|c|c|c|c|c|}
\hline \multirow[t]{3}{*}{ Subject } & \multirow[t]{3}{*}{ Sex } & \multirow[t]{3}{*}{ Treatment } & \multicolumn{6}{|c|}{ Quality of life questionnaires } \\
\hline & & & \multicolumn{3}{|c|}{ SF-36 } & \multicolumn{3}{|c|}{ PDI } \\
\hline & & & ISA & FSA & $\%$ increase & ISA & FSA & $\%$ decrease \\
\hline 1 & $\mathrm{~F}$ & $\mathrm{C}, \mathrm{BPT}$ & 2615 & 3460 & 32.3 & 12 & 2 & 83 \\
\hline 2 & $\mathrm{~F}$ & $\mathrm{C}$ & 2775 & 3050 & 9.9 & 5 & 3 & 40 \\
\hline 3 & M & $\mathrm{AB}$ & 2930 & 3310 & 12.9 & 5 & 1 & 80 \\
\hline 4 & $\mathrm{~F}$ & $\mathrm{AB}, \mathrm{BPT}$ & 1525 & 2635 & 72.7 & 10 & 0 & 100 \\
\hline 5 & $\mathrm{~F}$ & $\mathrm{C}, \mathrm{AB}, \mathrm{PT}, \mathrm{BPT}$ & 1895 & 2510 & 32.4 & 8 & 1 & 87.5 \\
\hline 6 & $\mathrm{~F}$ & C, PT, BPT & 2925 & 3450 & 17.9 & 13 & 0 & 100 \\
\hline 7 & M & $\mathrm{AB}, \mathrm{BPT}$ & 3240 & 3260 & 0.61 & 2 & 0 & 100 \\
\hline 8 & M & BPT & 1990 & 2900 & 45.7 & 14 & 0 & 100 \\
\hline 9 & $\mathrm{~F}$ & $\mathrm{BPT}$ & 2775 & 3550 & 27.9 & 8 & 0 & 100 \\
\hline 10 & M & $\mathrm{C}, \mathrm{AB}, \mathrm{PT}$ & 3120 & 3100 & -0.6 & 2 & 0 & 100 \\
\hline 11 & M & C, PT, BPT, & 2465 & 3410 & 38.3 & 10 & 3 & 70 \\
\hline 12 & M & $\mathrm{C}$ & 2820 & 3010 & 6.7 & 4 & 4 & 0 \\
\hline 13 & $\mathrm{~F}$ & C, PT, BPT & 2275 & 3475 & 52.7 & 10 & 2 & 80 \\
\hline 14 & M & $\mathrm{C}, \mathrm{AB}, \mathrm{PT}, \mathrm{BPT}$ & 2885 & 3075 & 6.5 & 3 & 0 & 100 \\
\hline
\end{tabular}

SF-36: Short Form 36 Health Survey; PDI: Psoriasis Disability Index; M: male; F: female; ISA: initial score average; FSA: final score average. F: female; M: male; AB: artificial balneotherapy; PT: phototherapy; BPT: balneophototherapy.

\section{DISCUSSION}

The aim of this study was to compare the effectiveness of AB, PT and BPT in the treatment of plaque psoriasis, evaluating the plaque area, alteration of skin pigmentation, PASI score and quality-of-life assessment by SF-36 and Psoriasis PDI scores during only one month of treatment. 
The plaque area is one of the most important variables when evaluating psoriasis, since it is associated to the severity of the disease. Several studies have focused on searching an objective method of quantifying the affected skin area (Cannavò et al., 2017). In the study of Ihtatho et al. (2007), instead of using the ImageJ software, they used the CIELab method for the extraction of hue and color parameters in order to differentiate healthy and psoriatic skin. However, this method does not discriminate eyes, lips or hair from the rest of the body surface. In the study by Delgado Gomez et al. (2002), the Gabor filter was used, but it was unable to detect plaques covered with white scales. In the two studies mentioned above, plaques covered by hair were also not detected. Therefore, manual plaque separation, as performed in the present study, continues to be a more reliable method. It allows for direct differentiation of hair, scales and other structures that may hinder the measurement.

We showed that plaques treated by PT presented a significant area decrease. However, the combination of PT and $\mathrm{AB}$ (BPT) elicited a more pronounced reduction of plaque area. This may have occurred because, even though PT by itself is an effective psoriasis treatment, by removing the scaly layer of the plaques, the application of $A B$ strengthens its effects, letting the UV-B light get through to the skin more freely, accelerating the migration of Langerhans cells and reducing psoriasis immunological response (Wong et al.).

It is important to mention that the study was carried out during the summer, so the erythema attenuation percentages may have been affected by direct exposure UV$\mathrm{B}$ radiation from the sun, which according to Calle et al. (2009), causes inhibition of cellular hyperproliferation. Therefore, the $\sim 6 \%$ attenuation of erythema score by $\mathrm{AB}$ treatment may have an interference of natural UV light. However, $\mathrm{AB}$ is an alternative therapy that is recommended especially in patients with contraindications to UV-B radiation exposure as occurred in the study by Gisondi et al. (2012) on which there was high adherence to alternative treatments.

The group treated with PT had a decrease of $\sim 9 \%$ on the red color values of their plaques, indicating that the treatment was effective for erythema attenuation. This, can be attributed to the effects of UV-B radiation on cytokines production, apoptosis induction, acceleration of Langerhans cell migration and decrease of T-lymphocytes surrounding the epidermis, reducing inflammatory response and erythema (Londoño et al.).

The $1.34 \%$ attenuation of erythema values by BPT was not significant. The mechanisms of action of BPT are still being elucidated (Gambichler et al.). The may exert mechanical, chemical and thermal effects that are immunomodulatory, alleviating some aspects of psoriasis pathogenesis and, thus, strengthening the PT effects. In the study of Léauté-Labrèze et al., the immersion caused the removal of the scaly layer from the psoriasis plaques. This may increase photosensitivity to UV-B radiation (SendraPortero, 1998), attenuating the plaque psoriasis redness, as determined by Schempp et al. (1997). In our study there was no clinical improvement in terms of erythema attenuation by BPT, which could be attributed to specific characteristics of each subject, such as skin type and emotional state. Léauté-Labrèze et al. concluded that $\mathrm{AB}$ had a minor therapeutic effect in the psoriasis treatment and that its strengthening effects on PT in order to produce erythema attenuation remains to be proved. Although there are not many studies which clearly determine the effects of BPT, Klein et al. (2011) showed significant clinical effects of synchronous BPT after 35 sessions of treatment.

The present study observed that severity may not be directly associated to the subject's perception, because most patients, in spite of having a mild psoriasis according to PASI, described it as more severe. This is in agreement with Arruda et al. (2011) that stated that the injury is classified by the patients as severe because it affects their quality of life significantly, even when it just involves a small area of the body. In our study, the scores from patients who presented plaques in visible areas such as arms, calves and feet revealed a more negative influence of those plaques on quality of life.

Psoriasis has social, physical and psychological effects on the patient. Furthermore, it has a negative impact on quality of life associated to health, as it was observed in this study, and is in agreement with the PDI validation study (Vanaclocha et al., 2005). We observed that psoriasis presented greater influence on the quality of life (mainly of women assessed through the SF-36 and PDI scores), which is in accordance to Sarilar et al. (2011).

In the present study, patients subjected to different treatments for psoriasis presented a reduction in complications associated to the disease (attenuated plaque area), regardless of sex or emotional condition (e.g, stress), improving quality of life, probably through the restoration of functionality and daily life activities.

All the assessments were made considering the fact that each participant had a different number of plaques and each plaque was randomly assigned to a specific treatment (Tables II and III). Therefore, it was not possible to make a complete intergroup comparison within the same subject, 
and the effects on quality of life improvement and psoriasis attenuation scores could not be attributed to a particular treatment. In conclusion, application of the physical agents used in this investigation attenuated the severity of psoriasis and improved quality of life of the patients after only 12 sessions of treatment during a one-month period. The BPT was most effective in controlling psoriasis by diminishing its area and PT by attenuating the erythema.

\section{ACKNOWLEDGMENTS}

The authors would like to thank Mauricio Garrido for their contribution on writing the manuscript and Ximena Jara and Hugo Tapia for the scientific advisory.

NORAMBUENA-MARDONES, L.; PINTO-DAZA, D. E.; TRONCOSO-FERNÁNDEZ, K. D.; PACHECO,A.; VITZEL, K. F. \& MARZUCA-NASSR, G. N. Efectividad del tratamiento a corto plazo de los agentes físicos en la morfología macroscópica de las placas de psoriasis. Int. J. Morphol., 37(4):1541-1550, 2019.

RESUMEN: La Psoriasis es una enfermedad inflamatoria crónica que presenta irritación cutánea que puede derivar a placas. El objetivo de este trabajo fue comparar la efectividad del tratamiento a corto plazo con agentes físicos en la morfología macroscópica (área y eritema) en pacientes con placas de psoriasis. Estudio experimental, prospectivo, randomizado. Catorce sujetos participaron con diagnóstico médico de psoriasis, con más de una placa en la piel y sin tener tratamiento tópico de forma voluntaria. Todos los sujetos completaron el estudio, el cual consistió de 12 sesiones de tratamiento dividido en grupo control (C), BA, FT y BFA. Posterior a la sesión 12, se observó una reducción significativa en toda el área de las placas que recibieron tratamiento al compararlas al grupo C y el grupo BFA fue el más efectivo. Sin embargo, solo los grupos BA y FT presentaron una reducción del eritema. Respecto a la severidad, 9 pacientes cambiaron de la baja categoría en el test de PASI y 5 de ellos se mantuvieron en el nivel medio, pero disminuyeron su puntaje. Finalmente, 13 de 14 sujetos mejoraron su calidad de vida. Los agentes físicos usados redujeron la severidad de la psoriasis y mejoraron la calidad de vida de los pacientes después de 12 sesiones de tratamiento durante el período de un mes. La BFA fue la más efectiva en controlar la psoriasis por la disminución en el área y la FT por la atenuación del eritema.

PALABRAS CLAVE: Psoriasis; Balneoterapia; Fototerapia; Balneofototerapia.

\section{REFERENCES}

Arruda, C. S.; Nogueira, E.; de Oliveira, M. S.; Pereira, E. R. \& Silva, R. M. Advances and challenges of nursing in the scientific production on Psoriasis. Rev. Bras. Enferm., 64(1):168-75, 2011.
Batycka-Baran, A.; Besgen, P.; Wolf, R.; Szepietowski, J. C. \& Prinz, J. C. The effect of phototherapy on systemic inflammatory process in patients with plaque psoriasis. J. Photochem. Photobiol. B, 161:396-401, 2016.

Calle, J.; Rivas, A. M.; Ruiz, M. C.; Sánchez, M. A.; Trujillo, M. C.; Jiménez, S. B. \& Zuluaga, A. Manejo de la psoriasis con luz ultravioleta A más psoraleno (PUVA) y luz ultravioleta B (UVB). Rev. Asoc. Colomb. Dermatol. Cir. Dermatol., 17(3):162-71, 2009.

Cannavò, S. P.; Guarneri, F.; Giuffrida, R.; Aragona, E. \& Guarneri, C. Evaluation of cutaneous surface parameters in psoriatic patients. Skin Res. Technol., 23(1):41-7, 2017.

Delgado Gomez, D.; Jensen, T. K.; Darkner, S. \& Carstensen, J. M. Automated visual scoring of psoriasis. Inform. Math. Model., 1:1-8, 2002.

Finlay, A. Y.; Khan, G. K.; Luscombe, D. K. \& Salek, M. S. Validation of sickness impact profile and psoriasis disability index in psoriasis. $\mathrm{Br}$. J. Dermatol., 123(6):751-6, 1990.

Gambichler, T.; Terras, S. \& Skrygan, M. Cyclooxygenase 2 expression and apoptosis in normal and psoriatic epidermis models exposed to salt water soaks and narrowband ultraviolet B radiation. J. Eur. Acad. Dermatol. Venereol., 29(1):180-3, 2015.

Gisondi, P.; Farina, S.; Giordano, M. V.; Zanoni, M. \& Girolomoni, G. Attitude to treatment of patients with psoriasis attending spa center. $G$. Ital. Dermatol. Venereol., 147(5):483-9, 2012.

Heckman, C. J.; Chandler, R.; Kloss, J. D.; Benson, A.; Rooney, D.; Munshi, T.; Darlow, S. D.; Perlis, C.; Manne, S. L. \& Oslin, D. W. Minimal Erythema Dose (MED) testing. J. Vis. Exp., (75):e50175, 2013.

Ihtatho, D.; Fadzil, M. H.; Affandi, A. M. \& Hussein, S. H. Area assessment of psoriasis lesion for PASI scoring. Conf. Proc. I. E. E. E. Eng. Med. Biol. Soc., 2007:3446-9, 2007.

Katz, U.; Shoenfeld, Y.; Zakin, V.; Sherer, Y. \& Sukenik, S. Scientific evidence of the therapeutic effects of dead sea treatments: a systematic review. Semin. Arthritis Rheum., 42(2):186-200, 2012.

Klein, A.; Schiffner, R.; Schiffner-Rohe, J.; Einsele-Krämer, B.; Heinlin, J.; Stolz, W. \& Landthaler, M. A randomized clinical trial in psoriasis: synchronous balneophototherapy with bathing in Dead Sea salt solution plus narrowband UVB vs. narrowband UVB alone (TOMESA-study group). J. Eur. Acad. Dermatol. Venereol., 25(5):570-8, 2011.

Kogan, N.; Raimondo, N.; Gusis, S. E.; Izcovich, A.; Abarca Duran, J. A.; Barahona-Torres, L.; Blanco, O.; Quintana, G. B.; Briones, M. C.; Castro, C.; et al. Latin American Clinical Practice Guidelines on the Systemic Treatment of Psoriasis SOLAPSO - Sociedad Latinoamericana de Psoriasis (Latin American Psoriasis Society). Int. J. Dermatol., 58 Suppl. 1:4-28, 2019.

Léauté-Labrèze, C.; Saillour, F.; Chêne, G.; Cazenave, C.; Luxey-Bellocq, M. L.; Sanciaume, C.; Toussaint, J. F. \& Taïeb, A. Saline spa water or combined water and UV-B for psoriasis vs conventional UV-B: lessons from the Salies de Béarn randomized study. Arch. Dermatol., 137(8):1035-9,2001.

Londoño, A.; Gaviria, V. C.; Sánchez, S. M. \& Ordóñez, M. J. Comparison of the effectiveness of psoralen plus ultraviolet A light (PUVA) and ultraviolet B narrow band (UVB-NB) in the treatment of psoriasis. Rev. Fac. Nac. Salud Pública, 27(3):322-8, 2009.

Olivares, P. Perfil del Estado de Salud de Beneficiarios de Isapres: Informe Preliminar. Santiago de Chile, Departamento de Estudio, Superintendencia de Salud, 2005.

Puig, L. ¿Es realmente útil el PASI como parámetro de la gravedad de la psoriasis?. Piel, 22(8):367-9, 2007.

Sarilar, M.; Koic, E. \& Dervinja, F. Personal experiences of the psoriasis and its relation to the stressful life events. Coll. Antropol., 35 Suppl. 2:241-3, 2011.

Schempp, C. M.; Blümke, C.; Schöpf, E. \& Simon, J. C. Skin sensitivity to UV-B radiation is differentially increased by exposure to water and different salt solutions. Arch. Dermatol., 133(12):1610, 1997.

Schempp, C. M.; Müller, K.; Schulte-Mönting, J.; Schöpf, E. \& Simon, J. C. Salt water bathing prior to UVB irradiation leads to a decrease of the minimal erythema dose and an increased erythema index without affecting skin pigmentation. Photochem. Photobiol., 69(3):341-4, 1999. 
Schiener, R.; Brockow, T.; Franke, A.; Salzer, B.; Peter, R. U. \& Resch, K. L. Bath PUVA and saltwater baths followed by UV-B phototherapy as treatments for psoriasis: a randomized controlled trial. Arch. Dermatol., 143(5):586-96, 2007.

Schmitt, J. \& Wozel, G. The psoriasis area and severity index is the adequate criterion to define severity in chronic plaque-type psoriasis. Dermatology, 210(3):194-9, 2005.

Sendra-Portero, F. Radiación Ultravioleta. In: Martínez Morillo, M.; Pastor Vega, J. M. \& Sendra Portero, F. (Eds.). Manual de Medicina Física. Madrid, Harcourt Brace, 1998. pp.276-86.

Sereflican, B.; Goksugur, N.; Bugdayci, G.; Polat, M. \& Haydar Parlak, A. Serum Visfatin, Adiponectin, and Tumor Necrosis Factor Alpha (TNFa) Levels in Patients with Psoriasis and their Correlation with Disease Severity. Acta Dermatovenerol. Croat., 24(1):13-9, 2016.

Vanaclocha, F.; Puig, L.; Daudén, E.; Escudero, J.; Hernanz, J. M.; Ferrándiz, C.; Febrer, I.; Lizán, L. \& Badia, X. Validation of the Spanish version of the Psoriasis Disability Index questionnaire in assessing the quality of life of patients with moderate-severe psoriasis. Actas Dermosifiliogr., 96(10):659-68, 2005.

Wong, T.; Hsu, L. \& Liao, W. Phototherapy in psoriasis: a review of mechanisms of action. J. Cutan. Med. Surg., 17(1):6-12, 2013.
Corresponding author:

Prof. Gabriel Nasri Marzuca Nassr, PhD

Department of Internal Medicine

Faculty of Medicine

Universidad de La Frontera

Temuco 4780000

CHILE

Email: gabriel.marzuca@ufrontera.cl

Received: 20-01-2019

Accepted: 19-06-2019 